\title{
Merging paleobiology with conservation biology to guide the future of terrestrial ecosystems
}

\section{Barnosky, Anthony D.}

2017-02-10

Barnosky , A D , Hadly , E A , Gonzalez , P , Head , J , Polly , P D , Lawing , A M , Eronen , J T , Ackerly, D D , Alex , K, Biber , E, Blois , J, Brashares , J, Ceballos , G, Davis , E , Dietl , G P , Dirzo , R, Doremus , H, Fortelius , M , Greene , H W , Hellmann , J , Hickler , T , Jackson , S T , Kemp , M , Koch , P L , Kremen , C , Lindsey , E L , Looy , C , Marshall , C R, Mendenhall , C , Mulch , A, Mychajliw , A M , Nowak, C, Ramakrishnan , U , Schnitzler , J , Das Shrestha , K, Solari , K, Stegner , L , Stegner , M A, Stenseth , N C, Wake , M H \& Zhang , Z 2017, ' Merging paleobiology with conservation biology to guide the future of terrestrial ecosystems ' , Science , vol. 355 , no. 6325 , eaah4787 . https://doi.org/10.1126/science.aah4787

http://hdl.handle.net/10138/308891

https://doi.org/10.1126/science.aah4787

unspecified

acceptedVersion

Downloaded from Helda, University of Helsinki institutional repository.

This is an electronic reprint of the original article.

This reprint may differ from the original in pagination and typographic detail.

Please cite the original version. 
REVIEW SUMMARY-PRINT VERSION

ECOLOGY

\section{No Going Back:-Merging Paleobiology With Conservation Biology to Guide the Future of Terrestrial Ecosystems}

Anthony D. Barnosky*, Elizabeth A. Hadly, Patrick Gonzalez, Jason Head, P. David Polly, A.

Michelle Lawing, Jussi T. Eronen, David D. Ackerly", Ken Alex, Eric Biber, Jessica Blois, Justin Brashares, Gerardo Ceballos, Edward Davis, Gregory P. Dietl, Rodolfo Dirzo, Holly

Doremus, Mikael Fortelius, Harry Greene, Jessica Hellmann, Thomas Hickler, Stephen T.

Jackson, Melissa Kemp, Paul L. Koch, Claire Kremen, Emily L. Lindsey, Cindy Looy, Charles

R. Marshall, Chase Mendenhall, Andreas Mulch, Alexis M. Mychajliw, Carsten Nowak, Uma

Ramakrishnan, Jan Schnitzler, Kashish Das Shrestha, Katherine Solari, Lynn Stegner, M. Allison

Stegner, Nils Chr. Stenseth, Marvalee H. Wake, Zhibin Zhang

* Corresponding author. E-mail: tonybarnosky@stanford.edu

"Authors after the first seven are listed alphabetically

BACKGROUND: The pace and magnitude of human-caused global change has accelerated dramatically over the past fifty years, overwhelming the capacity of many ecosystems and species to maintain themselves as they have under the more stable conditions that prevailed for at least 11,000 years. The next few decades threaten even more rapid transformations, because by 2050 the human population is projected to grow by three billion while simultaneously increasing 
per capita consumption. Thus, to avoid losing many species and the crucial aspects of ecosystems that we need — for both our physical and emotional wellbeing — new conservation paradigms and integration of information from conservation biology, paleobiology, and the Earth sciences are required.

ADVANCES: Rather than attempting to hold ecosystems to an idealized conception of the past, as has been the prevailing conservation paradigm until recently, maintaining vibrant ecosystems for the future now requires new approaches that use both historical and novel conservation landscapes, enhance adaptive capacity for ecosystems and organisms, facilitate connectedness, and manage ecosystems for functional integrity rather than focusing entirely on particular species. Scientific breakthroughs needed to underpin such a paradigm shift are emerging at the intersection of ecology and paleobiology, revealing: (i) which species and ecosystems will need human intervention to persist; (ii) how to foster population connectivity that anticipates rapidly changing climate and land use; (iii) functional attributes that characterize ecosystems through thousands to millions of years irrespective of the species that are involved; and (iv) the range of compositional and functional variation that ecosystems have exhibited over their long histories. Such information is necessary for recognizing which current changes foretell transitions to less robust ecological states, and which changes may signal benign ecosystem shifts that will cause no substantial loss of ecosystem function or services.

Conservation success will also increasingly hinge on choosing among different, sometimes mutually exclusive approaches to best achieve three conceptually distinct goals: maximizing biodiversity, maximizing ecosystem services, and preserving wilderness. These goals vary in applicability depending on whether historical or novel ecosystems are the 
conservation target. Tradeoffs already occur: for example, managing to maximize certain ecosystem services upon which people depend (e.g., food production on farm or rangelands) versus maintaining healthy populations of vulnerable species (e.g., wolves, lions, or elephants). In the future, the choices will be starker, likely involving decisions such as which species are candidates for managed relocation and to which areas, and whether certain areas should be off limits for intensive management, even if it means losing some species that now live there. Developing the capacity to make those choices will require conservation in both historical and novel ecosystems, and effective collaboration of scientists, governmental officials, nongovernmental organizations, the legal community, and other stakeholders.

\section{Insert Gorilla Picture Here}

OUTLOOK: Conservation efforts are currently in a state of transition, with active debate about the relative importance of preserving historical landscapes with minimal human impact on one end of the ideological spectrum, versus manipulating novel ecosystems that result from human activities on the other. While the two approaches are often presented as dichotomous, in fact they are connected by a continuum of practices, and both are needed. In most landscapes, maximizing conservation success will require more integration of paleobiology and conservation biology, because in a rapidly changing world, a long-term perspective (encompassing at least millennia) is necessary to specify and select appropriate conservation targets and plans. While adding this long-term perspective will be essential to sustain biodiversity and all of the facets of nature that humans need as we continue to rapidly change the world over the next few decades, maximizing the chances of success will also require dealing with the root causes of the conservation crisis: rapid growth of the human population, increasing per capita consumption especially in 
developed countries, and anthropogenic climate change that is rapidly pushing habitats outside the bounds experienced by today's species.

\section{Figure Legend For Gorilla Picture}

Fewer than 900 mountain gorillas are left in the world and their continued existence depends upon the choices humans make, exemplifying the state of many species and ecosystems. Can conservation biology save biodiversity and all the aspects of nature people need and value as three billion more of us are added to the planet by 2050 , while climate continues to change to states outside the bounds that most of today's ecosystems have ever experienced? [Photo credit: E.A. Hadly, at Volcanoes National Park, Rwanda] 
REVIEW - ONLINE TEXT

\section{Title:}

\section{No Going Back: Merging Paleobiology With Conservation Biology to Guide the Future of Terrestrial Ecosystems}

\section{Authors:}

Anthony D. Barnosky ${ }^{1}$, Elizabeth A. Hadly ${ }^{2}$, Patrick Gonzalez ${ }^{3}$, Jason Head ${ }^{4}$, P. David Polly ${ }^{5}$, A. Michelle Lawing ${ }^{6}$, Jussi T. Eronen ${ }^{7}$, David D. Ackerly ${ }^{8}$, Ken Alex $^{9}$, Eric Biber ${ }^{10}$, Jessica Blois $^{11}$, Justin Brashares ${ }^{12}$, Gerardo Ceballos ${ }^{13}$, Edward Davis ${ }^{14}$, Gregory P. Dietl ${ }^{15}$, Rodolfo Dirzo $^{16}$, Holly Doremus ${ }^{17}$, Mikael Fortelius ${ }^{18}$, Harry Greene ${ }^{19}$, Jessica Hellmann ${ }^{20}$, Thomas Hickler $^{21}$, Stephen T. Jackson ${ }^{22}$, Melissa Kemp ${ }^{23}$, Paul L. Koch ${ }^{24}$, Claire Kremen ${ }^{25}$, Emily L. Lindsey $^{26}$, Cindy Looy ${ }^{27}$, Charles R. Marshall ${ }^{28}$, Chase Mendenhall ${ }^{29}$, Andreas Mulch ${ }^{30}$, Alexis M. Mychajliw ${ }^{31}$, Carsten Nowak ${ }^{32}$, Uma Ramakrishnan ${ }^{33}$, Jan Schnitzler $^{34}$, Kashish Das Shrestha $^{35}$, Katherine Solari ${ }^{36}$, Lynn Stegner ${ }^{37}$, M. Allison Stegner ${ }^{38}$, Nils Chr. Stenseth ${ }^{39}$, Marvalee H. Wake ${ }^{40}$, Zhibin Zhang ${ }^{41}$

* Corresponding author. E-mail: tonybarnosky@stanford.edu

"Authors after the first seven are listed alphabetically 


\section{Affiliations:}

${ }^{1}$ Jasper Ridge Biological Preserve, Stanford University, Stanford, CA 94305 and Department of Integrative Biology and Museums of Paleontology and Vertebrate Zoology, University of California, CA Berkeley 94720 USA

${ }^{2}$ Department Biology, Department of Geological Sciences, Woods Institute for the Environment, Center for Innovations in Global Health, Jasper Ridge Biological Preserve, Stanford University, Stanford, California 94303 USA

${ }^{3}$ Natural Resource Stewardship and Science, U.S. National Park Service, Berkeley, CA 94720 USA; Department of Environmental Science, Policy, and Management, University of California, Berkeley, CA 94720 USA

${ }^{4}$ Department of Zoology, University of Cambridge, Downing Street, Cambridge, CB2 3EJ, United Kingdom

${ }^{5}$ Department of Geological Sciences, Indiana University, Bloomington, IN 47405

${ }^{6}$ Department of Ecosystem Science and Management, Texas A\&M University, College Station, TX 77845 USA

${ }^{7}$ Senckenberg Biodiversity and Climate Research Centre (BiK-F), Senckenberganlage 25, 60325 Frankfurt, Germany and Department of Geosciences and Geography, University of Helsinki, P.O. Box 64, FIN-00014, Finland and BIOS Research Unit, Kalliolanrinne 4, Helsinki, Finland

${ }^{8}$ Department of Integrative Biology, University and Jepson Herbaria, University of California, Berkeley, CA 94720 USA

${ }^{9}$ California Governor's Office of Planning and Research, P.O. Box 3044, Sacramento, CA 95812-3044

${ }^{10}$ School of Law, University of California, Berkeley, CA 94720 USA

${ }^{11}$ School of Natural Sciences, University of California, Merced, CA 95343 USA 
${ }^{12}$ Department of Environmental Science, Policy, and Management, University of California, Berkeley, CA 9472 USA

${ }^{13}$ Laboratorio de Ecologia y Conservacion de Fauna Silvestre, Instituto de Ecologia, UNAM, Ciudad Universitaria Ap. Post. 70-275 Mexico, D.F. 04510 Mexicode Ecologia, UNAM Ciudad Universitaria Ap. Postal 70-275 Mexico, D.F. 04510 Mexico

${ }^{14}$ Department of Geological Sciences, University of Oregon, Eugene, OR 97403 USA

${ }^{15}$ Paleontological Research Institution, 1259 Trumansburg Road, Ithaca, NY 14850 USA and Department of Earth and Atmospheric Sciences, Cornell University, Ithaca, NY 14853

${ }^{16}$ Department Biology, Stanford University, Stanford, California 94303 USA

${ }^{17}$ School of Law, University of California, Berkeley, CA 94720 USA

${ }^{18}$ Department of Geosciences and Geography, P.O. Box 64, FI-00014 University of Helsinki, Finland and Centre for Ecological and Evolutionary Synthesis, University of Oslo, P.O. Box 1066 Blindern, N- 1 0316 Oslo, Norway

${ }^{19}$ Department of Ecology and Evolutionary Biology, Cornell University, Ithaca, NY 14853 USA

${ }^{20}$ Institute of the Environment, University of Minnesota, Minneapolis, MN 55455 USA

${ }^{21}$ Senckenberg Biodiversity and Climate Research Centre (BiK-F) \& Institute of Physical Geography, Goethe-University Frankfurt, Senckenberganlage 25, D-60325 Frankfurt am Main Germany

${ }^{22}$ Department of Interior Southwest Climate Science Center, U.S. Geological Survey, and Department of Geosciences, University of Arizona, 1064 E. Lowell St., Tucson, AZ 85721

${ }^{23}$ Center for the Environment, Harvard University, Cambridge, MA 02138 USA

${ }^{24}$ Department of Earth and Planetary Sciences, University of California, Santa Cruz, CA 95064 USA

${ }^{25}$ Department of Environmental Science, Policy, and Management, University of California, Berkeley, CA 9472 USA

${ }^{26}$ Department of Integrative Biology and Museum of Paleontology, University of California, CA Berkeley 94720 US 
${ }^{27}$ Department of Integrative Biology, Museum of Paleontology, University and Jepson Herbaria, University of California, CA Berkeley 94720 USA

${ }^{28}$ Department of Integrative Biology and Museum of Paleontology, University of California, CA Berkeley 94720 USA

${ }^{29}$ Center for Conservation Biology, Stanford University, Stanford, CA 94305 and The Nature Conservancy, Arlington, VA 22203 USA

${ }^{30}$ Senckenberg Biodiversity and Climate Research Centre (BiK-F) 60325 Frankfurt am Main \& Institute of Geosciences, Goethe-University Frankfurt, 60438 Frankfurt am Main, Germany

${ }^{31}$ Department Biology, Stanford University, Stanford, California 94303 USA

${ }^{32}$ Senckenberg Research Institute and Natural History Museum Frankfurt, Clamecystr. 12, D-63571 Gelnhausen, Germany

${ }^{33}$ National Centre for Biological Sciences, Tata Institute of Fundamental Research GKVK, Bellary Road, Bangalore 560065, India

${ }^{34}$ Institute of Biology, Leipzig University, Johannisallee 21-23, 04103 Leipzig, Germany \& Senckenberg Biodiversity and Climate Research Centre (BiK-F), Senckenberganlage 25, 60325 Frankfurt am Main, Germany

${ }^{35}$ City Museum, Kathmandu, Nepal

${ }^{36}$ Department Biology, Stanford University, Stanford, California 94303 USA

${ }^{37}$ San Francisco, California USA

${ }^{38}$ Department of Integrative Biology and Museum of Paleontology, University of California, CA Berkeley 94720 USA

${ }^{39}$ Centre for Ecological and Evolutionary Synthesis (CEES), University of Oslo, Department of Biosciences, University of Oslo, P.O. Box 1066, Blindern NO-0316, Oslo, Norway

${ }^{40}$ Department of Integrative Biology and Museum of Vertebrate Zoology, University of California, Berkeley, CA 94720 USA 
${ }^{41}$ State Key Laboratory of Integrated Management of Insects and Rodents, Institute of Zoology, Chinese Academy of Sciences, 1 Beichen West Road, Chaoyang District, Beijing 100101, P.R. China

\section{One Sentence Summary:}

In today's rapidly changing world, successful conservation programs will need to look to the fossil record in order to effectively foster adaptive capacity in both historical and novel ecosystems. 


\begin{abstract}
:
Conservation of species and ecosystems is increasingly difficult because anthropogenic impacts are pervasive and accelerating. Under this rapid global change, maximizing conservation success requires a paradigm shift from maintaining ecosystems in idealized past states toward facilitating their adaptive and functional capacities, even as species ebb and flow individually. Developing effective strategies under this new paradigm will require deeper understanding of the long-term dynamics that govern ecosystem persistence, and reconciliation of conflicts among approaches to conserving historical versus novel ecosystems. Integrating emerging information from conservation biology, paleobiology, and the Earth sciences is an important step forward on the path to success. Maintaining nature in all its aspects will also entail immediately addressing the overarching threats of growing human population, overconsumption, pollution and climate change.
\end{abstract}

\title{
Main Text:
}

Local and global stress on ecosystems, species, and populations_-already severe—will intensify in the near future as the number of people, land use, and consumption of natural resources increase and as anthropogenic climate change continues (1-3). Even now, it is no longer possible to effectively manage most ecosystems to maintain them in a historical state, as has been prevailing practice and theory in conservation biology (4-๑). Rather, a paradigm shift is underway, with new conservation goals aiming to maximize the capacity of ecosystems to adapt to current and impending changes (4-11).

Recent work highlights that achieving such goals will require understanding how ecological dynamics play out over time scales much longer than a human lifetime (12). Such 
information has long been known to be available from historical, paleobiological, and geological records $(10,13)$. However, scientists and land managers are still grappling with how to more fully integrate paleobiological information into conservation theory and decisions (Fig. 1).

\section{INSERT Fig. 1. Critical conservation decisions. NEAR HERE}

\section{The Current Conservation Landscape}

More than half of Earth's ice-free land has been converted for human use (14), tens of thousands of species have been transported around the globe (15), and species and populations are going extinct at highly elevated rates (16). As a result much, if not most, of the planet is now covered by novel ecosystems (6) (Fig 1, D), that is, those with assemblages of species or other characteristics that did not exist prior to pre-industrial times, which human activities have created, either intentionally or inadvertently. Here we include as novel ecosystems cropland, pastureland, timber plantations and land modified by logging and human-caused erosion and sedimentation, in total covering $\sim 47 \%$ of ice-free land (14). Urban and rural communities, roads, reservoirs, railways, and mining areas account for an additional $\sim 7 \%(14)$.

Historical ecosystems are defined loosely as those presumed to be operating as they have for at least centuries ( 6 ) (Fig. 1, B). They include some national parks and other large tracts of land that are often protected to some degree and are at most lightly inhabited by people. Although all historical ecosystems exhibit signs of human modification, ranging from millennia of manipulation by indigenous people to present-day anthropogenic climate change, their dynamics and species compositions seem to closely resemble those present for at least centuries and to be more heavily influenced by non-anthropogenic processes than by humans. Here we regard historical ecosystems as those that still have at least $70 \%$ of the habitats that were present 
500 years ago and that contain fewer than 5 people $/ \mathrm{km}^{2}$ (17). A subset of historical ecosystems retain at least $\sim 90 \%$ of habitats that have characterized them over at least the last five centuries and contain $<1$ person $/ \mathrm{km}^{2}$ (17). We refer to these places as wilderness; such wilderness comprises $\sim 26 \%$ of ice-free land (17).

In both novel and historical ecosystems, conservation efforts generally target three key goals: maximizing biodiversity, maintaining ecological structure and function, and maximizing ecosystem services. Conservation in historical ecosystems, however, differs from conservation of novel ecosystems in a fundamental aspect: in historical ecosystems, the three key conservation goals usually overlap substantially. For example, intact tropical forests, which are among the world's most important historical ecosystems, support the majority of Earth's terrestrial species, retain a general ecological structure that has persisted for at least tens of thousands of years (even considering the long integration of indigenous peoples into such systems), and as a result offer myriad ecosystem services ranging from carbon sequestration, to purifying water and air and provisioning food, to providing diverse aesthetic, emotional, and wilderness experiences for people. Thus, in historical ecosystems, most conservation goals can be maximized simultaneously by the overarching approach of minimizing human impact.

In contrast, in novel ecosystems, particularly under conditions of rapid global change, the conservation goals of maximizing biodiversity, maintaining particular ecological structures and functions, and provision of particular ecosystem services can diverge $(6,18)$, though in most cases the three goals exhibit at least some overlap (Fig. 1, E). For instance, rescuing a species threatened by climate change or habitat loss may require manipulating its genetic diversity (19) (Fig. 1, E1) and/or managed relocation into a geographic region and ecosystem in which the species has never lived (20) (Fig. 1, E2). While effective in conserving biodiversity and perhaps 
promoting certain ecosystem services, like tourism, such actions contradict other goals, for example, the hăñds-off philosophy of maximizing wilderness attributes (21). Less nuanced examples include zoos, botanic gardens, and well-designed urban landscapes, which will be essential in maximizing biodiversity, but which completely replace wilderness. At another end of the spectrum are agricultural landscapes, which maximize a necessary ecosystem service (food production) and can either severely depress biodiversity relative to pre-anthropogenic conditions, as in the case of monoculture farming, or help maintain biodiversity if designed to do so, as in some coffee farms in Costa Rica $(22,23)$ (Fig. 1, E3). Thus, in novel landscapes, deciding which goal to optimize can engender much debate among stakeholders, as can the very decision about whether a given landscape should be regarded as historical or novel (Fig 1, A).

\section{INSERT Table 1. Multiple Conservation Approaches NEAR HERE}

Such concerns lead to conflicting opinions about the relative importance of preserving large landscapes with minimal human impact (24-26) versus designing human-dominated ecosystems in ways that maximize particular conservation goals (27). In practice the two schools of thought both recognize a gradient of human impacts, that conservation only works when human values are articulated by multiple stakeholders to guide any given effort, and that threatened species and special landscapes and ecosystems should be preserved $(18,28,29)$. Nevertheless, the diverse viewpoints have led to developing and implementing a diverse menu of conservation approaches (18), some of which appear contradictory or even mutually exclusive (Table 1). Yet, when put in the context of making choices (Fig. 1) that recognize both historical and novel ecosystems and rapid global change, most have a place. 


\section{Critical Information From Paleobiology}

Under current global change, successful conservation outcomes for most approaches (Table 1) depend upon meaningful comparisons between modern conditions and long-term histories. The emerging discipline of conservation paleobiology $(10,30)$ is supplying necessary data, insights, and techniques through: (i) specifying long-term, fluctuating baselines required to understand how ecosystems, communities, species, populations, and genetic structure vary naturally through time and space and how they respond to major perturbations (10, 31-36); (ii) identifying scalable taxon-free metrics that allow attributes of ecosystems to be tracked over seasons, decades, centuries, millennia, and millions of years $(10,37)$; (iii) demonstrating biotic outcomes of many "natural experiments" in global change (30) ranging from major extinctions $(10,16,29,38)$ to rapid climate change $(10,39,40)$ to species invasions $(10,41)$; (iv) testing and refining models of biotic response to future environmental change $(10,35,42)$, and (v) tracking the long-term dynamics of ecosystems in ways relevant to assessing continued potential for ecosystem services $(12,43,44)$ and early warning signs of ecological state-shifts $(10,45)$.

The kinds of fossils that have provided such insights most commonly include phytoplankton and zooplankton, many kinds of plants (represented by fossil pollen, seeds, leaves, and wood), invertebrate animals with hard parts (such as mollusks), and vertebrate animals (represented by bones and teeth) (Fig. 2). Depositional environments in which these taxa commonly are fossilized include lakes, river valleys, rock shelters, and caves. The fossil samples recovered from such deposits are particularly useful because they often show high fidelity to the living communities from which they were drawn in terms of taxonomic composition and relative abundance, as demonstrated by taphonomic studies that assess how the same sampling vectors that build fossil assemblages sample modern communities $(10,46-49)$. Some of these favorable 
depositional environments occur in most biomes, opening possibilities to use paleobiological data in many conservation settings; therefore, it should not be assumed that paleontological information is not available if there has not been targeted exploration for appropriate fossil sites.

Less available for conservation uses are species restricted to areas where fossilization potential is low (e.g., upland areas lacking lakes, rivers, caves, or rock shelters), those whose taphonomy is not well-understood $(10,50)$, and those whose body parts are too fragile to fossilize on a regular basis, such as most insects and birds. Even so, some taxa with low fossilization potential are informative for conservation efforts when they are present: for instance, beetles found in lake sediments and peat illustrate a response to climate change that differs from the mammalian response (51), and bones of California condors have been critical in identifying their pre-anthropogenic diet (10). In general, Quaternary fossils (Pleistocene and Holocene) have proven especially informative for addressing conservation questions, but useful information has also come from much older fossil deposits, reaching back millions of years ( 34 , 37).

The analytical methods that allow comparing present with past fall into two main categories: taxon-based and taxon-free. Taxon-based methods are those that rely on the presence, absence, or abundances of certain taxa and their underlying diversity including genetic or phylogenetic differentiation. Taxon-free methods utilize metrics that reflect ecosystem function rather than structure; examples used in modern systems include assessing ecological network structure (52) and measuring biomass (53), functional traits (54), nutrient flow (43), net primary productivity (55), or ecosystem services $(7,43)$. Quantifying taxon-based and taxon-free attributes in the present alone does not capture the full range of conditions under which a given ecosystem can thrive, because most ecosystems (at least those that have not been created by 
humans) have persisted for thousands to millions of years. The taxon-based approach to link conservation paleobiology and biology has been used most so far, but current efforts to develop and use taxon-free methods hold considerable promise. Depending on the availability of fossils and the type of conservation question being asked, one or the other approach may be more appropriate.

\section{INSERT Fig. 2. Tracking community fluctuations through millennia NEAR HERE}

Historical or Novel. Taxon-based paleontological data are critical in deciding whether a given so-called "natural" landscape represents a historical or a novel ecosystem (Fig. 1, A). These methods rely on direct comparisons of the taxa that occupied a region in the past to those living there presently. By using superposed, taphonomically-understood and well-dated fossil samples (Fig. 2) to reconstruct successive snapshots of the past, it is possible to outline the range of taxonomic and relative-abundance variation that characterizes ecosystems as they fluctuate over thousands to tens of thousands of years, sometimes much more.

For a modern ecosystem to be considered historical (Fig. 1, B), its taxon assemblage and their abundances should fall within the range of past millennial-scale variation. For example, in the world's first national park, Yellowstone National Park, USA, paleontological data influenced critical management decisions by demonstrating that Yellowstone preserves a historical ecosystem. Fossil deposits verified that the area proposed in 1995 for the reintroduction of the gray wolf (Canis lupus) had indeed harbored wolves (up to their extirpation in the $20^{\text {th }}$ century) for more than 3000 years, that a principle prey species—elk—used the area for calving thousands of years ago as they still do today, and that almost all of the mammal species that had occupied the region for millennia are still present (13) (Fig. 1, C1). In this case, the conservation 
question arose first: were wolves and elk native to the region before the park was established? Exploration for the requisite fossil sites, previously unknown, ensued as part of the datagathering exercise prior to management actions. Further verification that Yellowstone still represents a historic ecosystem came from assessing impacts of climate change on small mammals: ancient DNA obtained from fossil rodents confirmed that, although genetic diversity, population sizes, and gene flow had fluctuated through time in response to climatic conditions, genotypes in the park now have been there for millennia (56). From the botanical perspective, palynological (fossil pollen) records show that the current vegetation has persisted with only minor fluctuations in abundance of dominant taxa for at least 8000 years (57).

Assessing Whether Historical Ecosystems Can Be Maintained. A critical question for many historical ecosystems is whether they will be able to persist in the same states in which they have existed for thousands of years, given rapid, intensifying environmental changes (Fig. 1, C). The taxon-based approaches summarized above provide useful answers through establishing the range of variation that taxon-based attributes exhibit through the perturbations an ecosystem experiences over thousands of years. The nature and magnitude of the perturbations can be assessed from the contemporaneous geologic record—for example, isotopic proxies for temperature, lake-level or tree-ring analyses for precipitation, or charcoal records in alluvial deposits and lake cores to track fire frequency. Modern-day changes in the taxon-based metric or in the suspected perturbing agent (for instance, climate change) that exceed the variation evident through millennia or longer may warn that a shift to a new ecological state is imminent. In such cases, the management choice is to either attempt to hold the system to historical conditions, which would require ever-more intensive interventions and may be impossible, or manage the system for adaptive capacity (4). 'Adaptive capacity' in this context is the ability of an 
ecosystem to "re-configure without significant changes in crucial functions or declines in ecosystem services" (58). Put another way, adaptive capacity is the ability of an ecosystem to avoid collapse as it makes the critical transition from its historical ecological state to a new state and to be as resilient in its new state as it was in its previous state.

\section{INSERT Fig. 3. Transformation of historical ecosystems NEAR HERE}

Robustly assessing adaptive capacity requires combining information about prehistoric conditions, modern and historic observations, and future projections. An illustrative example is the conservation of Joshua trees (Yucca brevifolia) in and around Joshua Tree National Park, California (Fig. 1, C2). The distribution of Joshua tree fossils preserved in wood rat middens (Fig. 2) and in the dung of extinct Shasta ground sloths (Nothrotheriops shastensis) demonstrated the sensitivity of the trees to increased temperature and aridity $\sim 11,700$ years ago, and also revealed that dispersal of the species occurred only slowly: 1-2 $\mathrm{m} \mathrm{y}^{-1}$ (59). Today, Joshua trees are only rarely reproducing within the park because of increased temperatures and drought, and climate projections under a medium greenhouse gas emissions scenario indicate that $90 \%$ of their suitable habitat in the park could be lost by 2100 (59). Climatically suitable areas may shift northward and upslope, but the slow migration rate of Joshua trees limits their ability to track their suitable climate space, especially since one of their dispersal agents—-Shasta ground sloths-is extinct. In this case, the fossil information implies that conserving Joshua Tree National Park in its present ecological state may not be possible because of climate-triggered species turnover, including loss of its namesake species and colonization by currently exotic species. The implication is that conserving Joshua tree ecosystems may require more active management in protected areas outside the national park, acquisition of new lands, and perhaps 
targeted planting. This landscape-scale management of Joshua trees could nurture the adaptive capacity of the species across its range, even if the national park loses its suitable habitat, while still maintaining the wilderness character of Joshua Tree National Park if wilderness character depends more on the low level of local human impacts than on the presence of Joshua trees.

Paleontological data show that other historical ecosystems have already begun to change and are vulnerable to future change, including fire-dependent ecosystems across western North America and Amazon tropical rain forests, which can rapidly shift to savanna (Fig. 3).

Comparisons of species dispersal rates to past and present velocity of climate change - the distance per unit of time that a species would need to move to remain in its current conditions of temperature or other climate variables (60) — have also proven useful in determining areas and species most at risk of ecological transformations. In general, such studies reveal that the speed at which species will need to move over the coming decades far outstrips the pace at which they actually did move in response to the most rapid climate change documented in the fossil record, the transition from the last glacial period into the Holocene (60). Such information indicates that the need to manage historical ecosystems for their adaptive capacity will increase, mandating increased use of taxon-free metrics (see below) to assess how well that management is proceeding.

Conservation in Novel Ecosystems. Landscapes that already fall outside historical norms (Fig. 1, D) — which in many cases is evident even without consideration of fossil data $(6,14)$ may be candidates for restoration to a desired historical state if the kinds of data described above verify that the system has not been pushed irreparably beyond its millennial-scale variation in taxonomic composition and abundance (10). This may be the case, for example, if the current system can be returned to its long-term state by reintroducing key taxa or genotypes. Where 
restoration is not possible or desirable (Fig. 1, E) — the situation for perhaps most of the ecosystems on the half of the planet that humans have transformed and that are changing even more under current anthropogenic pressures — novel ecosystems also provide many conservation opportunities (6). By definition, novel ecosystems are unique with respect to past ecosystems in terms of taxonomic composition; thus, in these cases taxon-free instead of taxon-based approaches provide the most effective applications of paleontological data to inform conservation strategies.

For example, paleontological analyses have shown that certain body-mass distributions (34), biomass patterns (29), numbers of species within trophic and size categories $(33,34)$, abundance patterns $(61)$, and ecological networks $(62,63)$ are characteristic of mammal communities that persist for thousands to millions of years, irrespective of the constituent species. This knowledge can answer critical questions, which abound, about the design and longterm viability of novel ecosystems, by considering the constituent species primarily in terms of ecological function rather than taxonomic identity. In urban settings, for example, do domestic cats carry out the function of extirpated or extinct meso-predators, keeping rodent and bird populations in check, which would indicate healthy ecological function, or is their impact greater than previously-present meso-predators, which might degrade ecosystem health? In ranchlands, is the biomass of livestock within the bounds of long-term megafauna variation, which once included mammoths and other extinct large mammals, or is the biomass of livestock presently greater? In managed relocation experiments, how will the transferred species affect trophic structure and ecological networks of the target ecosystems? And in rewilding initiatives—which can range from replacing "missing" taxa with the same species (e.g., wolves in Yellowstone and the Rewilding Europe effort (64)), to building ecosystems from scratch using functional analogs 
of extinct species (65)—what trophic structures and ecological networks will maximize biodiversity and ecosystem services and yield a system that is functionally robust to perturbations, thus keeping maintenance costs at a minimum?

Because taxon-free metrics can often be related to environmental parameters with statistical significance, they offer opportunities for understanding which kinds of species are likely to thrive in which regions as biota adjust to rapidly changing environmental conditions (Fig. 4). Such measures have been applied in modern community ecology $(54,66)$. In conservation paleobiology they have been called 'ecometrics' (37, 67-69), and include studies of both plants and animals, with a focus on functional traits that are frequently preserved in the fossil record. For plants this includes leaf size and shape (reflects precipitation patterns), stomatal index (measures equilibrium with atmospheric carbon dioxide), and phytolith shape (a proxy for resistance to herbivore use and whether or not the leaf wax hardened in a sunny or shady environment). Animal-based traits include dental morphology (which is a proxy for dietary diversity), locomotor attributes (which represent diversity in locomotion characteristic of different environments) (Fig. 4), and body size (which can reflect climate variables and nutrition). By focusing on such traits, it becomes possible to assess the ability of taxa to persist in particular places under particular scenarios of rapid environmental change. This in turn helps in identifying suitable candidates and locations for managed relocation, restoration, and rewilding programs (Fig. 1, E2).

\section{INSERT Fig. 4. Ecometrics in paleobiology NEAR HERE}

For example, in mammalian carnivore communities, locomotor diversity is known to be linked to vegetation cover $(68,70)$, which provides a valuable predictor of which carnivore 
species will be best suited to areas where climate change or other human impacts substantially alter plant communities, and also a metric by which to identify ecologically impoverished systems (Fig. 4). The application of such techniques requires that the linkage between a given trait and environmental parameter be firmly established, which so far has only been done for relatively few traits, especially in vertebrate animals. Future research that expanded the suite of useful traits would be useful.

Taxon-free paleontological measures can also reveal whether the potential for delivery of ecosystem services is being sustained in novel ecosystems, by tracking metrics that reflect ecological processes over centennial to millennial time-scales, such as nutrient cycling, biomass, crop production, water supply, climate regulation, timber, and coastal protection (43). Geologically-based proxies can track nutrient cycling, soil formation and stabilization, and erosion (43). As an example, a suite of fifty paleoenvironmental proxies demonstrated that since the year 1800 , rapid economic growth and population increases since the mid- $20^{\text {th }}$ century coincided with environmental degradation in the lower Yangtze Basin, China (44).

Finally, taxon-free paleontological data is critical for understanding whether certain ecosystems are approaching ecological thresholds $(10,45)$, so-called "tipping points," as demonstrated by analysis of diatoms, pollen, and sediments from lake cores, which identified a match between mathematical models and an ecological state-shift in Yunnan, China, and feedbacks that caused deforestation in one area to trigger an ecological state-shift in an adjacent area in Pennsylvania (10).

The utility of such taxon-free approaches for conservation paleobiology and predictive ecology has been demonstrated over the past decade by many case studies (71). A challenge going forward will be developing a coherent theoretical framework that takes into account such 
important relationships as the underlying trait distribution, performance filters that define trait fitness in varying environments, how traits will perform as environments change (71), spatial and temporal scaling and demography, and inter-and intraspecific variability in trait distribution and performance (72).

\section{Emerging Conservation Applications for Paleobiology}

Conservation Genetics (Fig. 1, E1). Conservation genetics is now being enhanced by studies of ancient DNA $(56,73)$. Besides establishing the long-term range of genetic diversity, population fluctuation, and gene flow as noted above for Yellowstone rodents (see Historical or Novel section) (73), paleontological studies also have resulted in new methods applicable to contemporary conservation problems, notably coalescent simulation analysis. This technique was developed to understand the relative contributions of gene flow and population size in explaining observed fluctuations in genetic diversity chronicled in ancient DNA $(73,74)$, but is now informing conservation strategies for presently threatened species. A case in point is one of the world's iconic mammals, tigers (Panthera tigris) (Fig. 5). Most tigers live in zoos and other captive situations; only $\sim 3800$ remain in the wild, and many of those are confined to novel ecosystems such as Ranthambore National Park, which has been heavily utilized by humans for more than a thousand years. Such small reserves can support just a few individuals, which has led to dwindling genetic diversity within populations. It has been unclear whether such bottlenecks presage extinction of tigers even in the few remaining habitats set aside for them. Coalescent simulation analyses used to forecast into the future instead of interpreting the past indicate that without substantial gene flow between reserves, reduced diversity will likely imperil tigers by the next century, but that diversity can be maintained and perhaps even enhanced by 
aggressively maintaining functional connectivity, physically moving individuals, and prioritizing breeding among reserves worldwide (19). Global conservation efforts thus far, however, tend to prioritize tiger numbers over connectivity, or focus on maintaining the "purity" of the genetic composition of tiger subspecies.

\section{INSERT Fig. 5. Pressures impacting wild tigers NEAR HERE}

Fossils have also figured prominently in experimentation with so-called "de-extinction" (75), efforts to reconstruct facsimiles of species that humans have driven to extinction either recently (passenger pigeons) or in the deeper past (mammoths). While such efforts may eventually create scientific curiosities, their conservation applications are at best limited (29), given that (i) the created genomes would be mostly composed of the base pairs of the nearest living relatives of the extinct species; (ii) epigenetic effects are not yet well understood; (iii) only a few individuals of a given species could be engineered because the process is both timeconsuming (due to gestation times) and very expensive; (iv) imparting the learned behavior that offspring gain from parental teaching would be impossible, because that knowledge went extinct with the lost species; (v) the ecosystems that supported many extinct species no longer exist, so survival outside of captivity would be difficult or impossible; and (vi) preventing the extinction of extant species and habitats numbering in the thousands already is challenging, so the prospects of sustaining "de-extincted" species are poor at best. Genetic engineering to simulate extinct life also raises ethical and legal concerns for many (76).

Invasive species (Fig 1, E4). Whether invasive species significantly alter ecological structure and function is a critical conservation question that can only be answered with a paleontological perspective. For instance, in California grassland ecosystems, historic cattle 
introduction transformed historic ecosystems into novel ones: as cattle populations grew, grazing megafauna biomass rose far above prehistoric levels, precipitating a functional shift in grazing pressure that favored replacement of native annual grasses by invasive species (77). The fossil record also can help inform controversial management decisions (41), such as whether wild horses on western North American ranch lands are invasive because they have been absent for most of the Holocene, or native because they evolved in those regions and were for millions of years an integral component of the ecosystems in which they are now thriving.

Enhancing connectivity (Fig. 1, E5). Corridors designed to connect protected areas, such as the Yellowstone to Yukon Conservation Initiative (Fig. 6) are critical today $(4,78)$ and will be become even more so in the near future, since one-tenth to one-half of global terrestrial area is highly vulnerable climate shifts in the $21^{\text {st }}$ century (79), whereas refugia in existing protected areas cover only $1-2 \%$ of global land (78). Therefore, a new perspective is that effective corridor design, besides taking into account present land-use, will need to identify key areas that have served as refugia in prehistory $(80)$ and anticipate ecological changes that will inevitably take place as climate changes $(81)$.

\section{INSERT Fig. 6. The importance of conservation corridors NEAR HERE}

Anticipating the future efficacy of corridors generally utilizes species distribution modeling (82). Most species distribution models rely on matching present or near-historic occurrences of a given species with nearby climatic parameters to estimate the ecological niche. Recent work that uses the same models combined with paleontologic, geologic, and paleoclimatic data to hindcast where species could have occurred over the past several thousand years $(35,42)$ reveals that in many cases, existing models do not adequately project where 
species may move in the future. In addition, incorporating prehistoric distributional information helps quantify the probability of errors (10). Using the fossil record to refine species distribution models requires parameterizing the climate models with appropriate boundary conditions as well as adequate dating control, which is now routinely achievable with AMS radiocarbon dates that place the age of critical fossils within decades.

The paleobiological approach of understanding functional relationships between taxonfree traits and environment (Fig. 4) can further improve species distribution models by incorporating information on trait-environment connections and persistent taxon associations; current models rely primarily on climatic parameters alone to estimate niche space. Such paleontologically-enhanced species distribution models can also be helpful in informing efforts to relocate species into suitable environments, ranging from managed relocation experiments that aim to save threatened species, to choosing which trees to plant in urban and suburban landscaping in order to jumpstart dispersal in anticipation of future climatic conditions.

Even with ideal corridors, however, species will not all respond in concert as climate changes, a lesson made clear by the fossil record (10). Some species will move quickly, some slowly and some not at all, and species will key on different aspects of global change, such as temperature, humidity or biotic interactions. Effective corridors will maximize the opportunities for such natural adjustments to proceed, even though the end result will be species assemblages almost certainly different than current or historical ones.

\section{Conservation Policy Implications}

Laws and governmental policies have played a critical role in conservation. Examples are numerous, ranging from the court-mediated Endangered Species Act in the United States, to extremes such as the "shoot-to-kill" policy for poachers in South Africa and Kenya. An open 
question under very rapid global change, however, is whether existing policies and laws are adequate to facilitate managing for the adaptive capacity of ecosystems, as opposed to simply mandating the presence of certain species $(9,83,84)$. Answering that question will require concerted interactions among conservation biologists, paleobiologists, and the policy and law communities nationally and internationally. A key challenge for paleobiologists and conservation biologists will be identifying ecological metrics that are meaningful for legislation.

\section{Conclusions and Outlook}

Effective conservation of biological resources now involves understanding and anticipating change in ecological systems in terms of adaptive capacity and ecosystem structure and function, knowledge that will become even more important in the future. The path forward requires enhanced use of information from the fossil and rock records in conservation planning and practice, combined with the coordination of conservation efforts situated in historical and novel ecosystems. Future efforts need to clearly differentiate between historical and novel ecosystems, identify key resiliencies and features of past ecosystems that may be generally applicable to the future, and characterize the functional interactions that persist in ecosystems for at least thousands of years. All of these tasks require integrating information from paleobiology, earth sciences, and conservation biology through use of both taxon-based and taxon-free analyses that allow parallel characterization and comparison of contemporary and past ecosystems. Taxon-free methods, which allow comparisons of functional attributes of past, present, and future ecosystems, regardless of the species involved, may prove especially useful for conservation efforts in novel ecosystems and for calibrating the extent of functional change that historical ecosystems will experience under ongoing and future global pressures. In addition 
to implementing these new approaches to conservation, it will be essential to deal with the root causes of the conservation crisis - rapid human population growth, overconsumption of goods and resources, and climate change - in order to keep nature diverse, adaptive, and able to fulfill the needs of the billions of people for whom Earth is the only home.

\section{REFERENCES AND NOTES}

1. UNDESA, World Population Prospects: The 2012 Revision, Volume II, Demographic Profiles (United Nations, Department of Economic and Social Affairs, Population Division, New York, 2013), vol. http://esa.un.org/wpp/Documentation/pdf/WPP2012_Volume-II-DemographicProfiles.pdf, pp. 439.

2. J. R. Oakleaf et al., A world at risk: Aggregating development trends to forecast global habitat conversion. PLoS One 10, e0138334. doi:0138310.0131371/journal.pone.0138334 (2015).

3. Y. Lu et al., Addressing China's grand challenge of achieving food security while ensuring environmental sustainability. Science Advances 1, e1400039 (2015).

4. B. A. Stein, P. Glick, N. Edelson, A. Staudt, Climate-Smart Conservation: Putting Adaptation Principles into Practice. (National Wildlife Federation, Washington, D.C., (eds.), 2014).

5. R. Colwell et al., Revisiting Leopold: Resource stewardship in the national parks. Report of the National Park System Advisory Board (National Park Service Advisory Board, Washington, D.C., 2012), pp. 1-24. 
6. R. J. Hobbs et al., Managing the whole landscape: historical, hybrid, and novel ecosystems. Frontiers in Ecology and the Environment 12, 557-564 (2014).

7. E. A. Chornesky et al., Adapting California's ecosystems to a changing climate. Bioscience, doi:10.1093/biosci/biu1233 (2015).

8. J. J. Hellmann, M. E. Pfrender, Future human intervention in ecosystems and the critical role for evolutionary biology. Conservation Biology 25, 1143-1147 (2011).

9. A. Camacho, H. Doremus, J. S. McLachlan, B. A. Minteer, Reassessing conservation goals in a changing climate. Issues in Science and Technoloy 26, http://issues.org/26$\underline{24 / p \_c a m a c h o /(2010) . ~}$

10. G. P. Dietl et al., Conservation paleobiology: leveraging knowledge of the past to inform conservation and restoration. Annual Review of Earth and Planetary Sciences 43, 79-103 (2015).

11. J. J. Lawler et al., The theory behind, and the challenges of, conserving nature's stage in a time of rapid change. Conservation Biology 29, 618-629 (2015).

12. A. Davies, M. J. Bunting, Applications of Palaeoecology in Conservation. The Open Ecology Journal 3, 54-67 (2010).

13. E. A. Hadly, Ecosystem dynamics through the past 2000 years as revealed by fossil mammals from Lamar Cave in Yellowstone National Park, USA. Historical Biology 8, $71-90$ (1994). 
14. R. L. B. Hooke, J. F. Martín-Duque, J. Pedraza, Land transformation by humans: A review. GSA Today 22, 1-10, doi: 10.1130/GSAT1151A.1131 (2012).

15. E. C. Ellis, E. C. Antill, H. Kreft, All Is not Loss: Plant biodiversity in the anthropocene. PLoS ONE 7, e30535. doi:30510.31371/journal.pone.0030535 (2012).

16. G. Ceballos et al., Accelerated modern human induced species losses: Entering the Sixth Mass Extinction. Science Advances 1, e1400253, DOI: 1400210.1401126/sciadv.1400253 (2015).

17. R. A. Mittermeier et al., Wilderness and biodiversity conservation. Proceedings of the National Academy of Science 100, 10309-10313 (2003).

18. G. M. Mace, Whose conservation? Science 345, 1558-1559 (2014).

19. R. A. Bay, U. Ramakrishnan, E. A. Hadly, A call for tiger management using "reserves" of genetic diversity. Journal of Heredity 105, 295-302 (2014).

20. M. W. Schwartz et al., Managed Relocation: Integrating the Scientific, Regulatory, and Ethical Challenges. Bioscience 62, $732-743$ (2012).

21. 88thCongressSecondSession, in Public Law 88-577 (16 U.S. C. 1131-1136), U. S. Congress, Ed. (United States Congress, Washington, D. C., 1964), vol. September 3, 1964, pp. http://www.wilderness.net/NWPS/documents//publiclaws/PDF/16 USC 11311136.pdf. 
22. C. D. Mendenhall, D. S. Karp, C. F. J. Meyer, E. A. Hadly, G. C. Daily, Predicting biodiversity change and averting collapse in agricultural landscapes. Nature 509, 213217 doi:210.1038/nature13139 (2014).

23. C. Kremen, Reframing the land-sparing/land-sharing debate for biodiversity conservation. Annals of the New York Academy of Sciences 1355, 52-76 doi: 10.1111/nyas.12845 (2015).

24. A. S. Leopold, S. A. Cain, C. M. Cottam, I. N. Gabrielson, T. Kimball, Wildlife Management in the National Parks: The Leopold Report. The National Park Service online publication (1963).

25. C. Meine, M. Soulé, R. F. Noss, “A Mission-Driven Discipline' ': the Growth of Conservation Biology. Conservation Biology 20, 631-651 (2006).

26. E. O. Wilson, Half Earth: Our Planet's Fight For Life. (Liveright W. W. Norton and Company, New York, 2016).

27. P. Kareiva, M. Marvier, R. Lalasz, Conservation in the Anthropocene, beyond solitude and fragility. The Breakthrough Winter, http://thebreakthrough.org/index.php/journal/past-issues/issue-2/conservation-in-theanthropocene (2012).

28. H. Tallis, J. Lubchenco, A call for inclusive conservation. Nature 515, 27-28 (2014).

29. A. D. Barnosky, Dodging Extinction: Power, Food, Money, and the Future of Life on Earth. (University of California Press, Berkeley, California, 2014). 
30. J. L. Gill et al., A 2.5-million-year perspective on coarse-filter strategies for conserving nature's stage. Conservation Biology 29, 640-648 (2015).

31. J. L. Blois, J. L. McGuire, E. A. Hadly, Small mammal diversity loss in response to latePleistocene climatic change. Nature 465, 771-774 (2010).

32. E. A. Hadly, Influence of late-Holocene climate on northern Rocky Mountain mammals. Quaternary Research 46, 298-310 (1996).

33. A. D. Barnosky et al., Exceptional record of mid-Pleistocene vertebrates helps differentiate climatic from anthropogenic ecosystem perturbations. Proceedings of the National Academy of Sciences USA 101, 9297-9302 (2004).

34. M. A. Stegner, M. Holmes, Using palaeontological data to assess mammalian community structure: Potential aid in conservation planning. . Palaeogeography, Palaeoclimatology, Palaeoecology 372, 138-146 (2013).

35. J. L. McGuire, E. B. Davis, Conservation paleobiogeography: the past, present, and future of species distributions. Ecogeography 37, 1092-1094 (2014).

36. NRC, The Geological Record of Ecological Dynamics, Understanding the Biotic Effects of Future Environmental Change. (National Research Council of the National Academies, Washington, DC, 2005).

37. J. T. Eronen et al., Ecometrics: The traits that bind the past and present together. Integrative Zoology 5, 88-101 (2010). 
38. P. L. Koch, A. D. Barnosky, Late Quaternary extinctions: state of the debate. Annual Review of Ecology, Evolution, and Systematics 37, 215-250 (2006).

39. J. L. Blois, E. A. Hadly, Mammalian response to Cenozoic climatic change. Annual Review of Earth and Planetary Sciences 37, 181-208, 110.1146/annurev.earth.031208.100055 (2009).

40. S. T. Jackson, J. L. Betancourt, R. K. Booth, S. T. Gray, Ecology and the ratchet of events: climate variability, niche dimensions, and species distributions. Proceedings of the National Academy of Sciences 106, 19685-19692 (2009).

41. J. J. Crees, S. T. Turvey, What constitutes a 'native' species? Insights from the Quaternary fossil record. Biological Conservation 186, 143-148 (2015).

42. K. C. Maguire, D. Nieto-Lugilde, M. Fitzpatrick, J. Williams, J. L. Blois, Modeling species and community responses to past, present, and future episodes of climatic and ecological change. Annual Review of Ecology, Evolution, and Systematics 46, 343-368 (2015).

43. E. S. Jeffers, S. Nogué, K. J. Willis, The role of palaeoecological records in assessing ecosystem services. Quaternary Science Reviews 112, 17-32 (2015).

44. J. A. Dearing et al., Extending the timescale and range of ecosystem services through paleoenvironmental analyses, exemplified in the lower Yangtze basin. Proceedings of the National Academy of Science 109, E1111-E1120 (2012). 
45. K. J. Willis, R. M. Bailey, S. A. Bhagwat, H. J. B. Birks, Biodiversity baselines, thresholds and resilience: testing predictions and assumptions using paleoecological data. Trends in Ecology \& Evolution 25, 583-591 (2010).

46. E. A. Hadly, Fidelity of terrestrial vertebrate fossils to a modern ecosystem. Palaeogeography Palaeoclimatology Palaeoecology 149, 389-409 (1999).

47. S. Porder, A. Paytan, E. A. Hadly, Mapping the origin of faunal assemblages using strontium isotopes. Paleobiology 29, 197-204 (2003).

48. R. C. Terry, On raptors and rodents: testing the ecological fidelity of cave deathassemblages through live-death analysis. Paleobiology 36, 137-160 (2010).

49. S. M. Kidwell, Biology in the Anthropocene: Challenges and insights from young fossil records. Proceeedings of the National Academy of Sciences 12, 4922-4929 (2015).

50. S. T. Jackson, Representation of flora and vegetation in Quaternary fossil assemblages: known and unknown knowns and unknowns. Quaternary Science Reviews 49, 1-15 (2012).

51. S. A. Elias, Differential insect and mammalian response to Late Quaternary climate change in the Rocky Mountain region of North America. Quaternary Science Reviews 120, 57-70 (2015).

52. J. M. Tylianakis, E. Laliberté, A. Nielsen, J. Bascompte, Conservation of species interaction networks. Biological Conservation 143, 2270-2279 (2010). 
53. I. A. Hatton et al., The predator-prey power law: Biomass scaling across terrestrial and aquatic biomes. Science 349, 1070 http://dx.doi.org/1010.1126/science.aac6284 (2015).

54. D. D. Ackerly et al., The evolution of plant ecophysiological traits: Recent advances and future directions. Bioscience 50, 979-995 (2000).

55. F. Krausmann et al., Global human appropriation of net primary production doubled in the 20th century. Proceedings of the National Academy of Science 110, 10324-10329 (2013).

56. E. A. Hadly et al., Genetic response to climatic change: Insights from ancient DNA and phylochronology. PLoS Biology 2, 1600-1609 (2004).

57. M. A. Huerta, C. Whitlock, J. Yale, Holocene vegetation-fire-climate linkages in northern Yellowstone National Park, USA. Palaeogeography, Palaeoclimatology, Palaeoecology 271, 170-181 (2009).

58. Resilience_Alliance, Key Concepts. Resilene Alliance Website April 17, 2016, http://www.resalliance.org/key-concepts (2016).

59. K. L. Cole et al., Past and ongoing shifts in Joshua tree distribution support future modeled range contraction. Ecological Applications 21: 137-149 21, 137-149 (2011).

60. N. S. Diffenbaugh, C. B. Field, Changes in ecologically critical terrestrial climate conditions. Science 341, 486-492 (2013). 
61. B. J. McGill, E. A. Hadly, B. A. Maurer, Community inertia of quaternary small mammal assemblages in North America. Proceedings of the National Academy of Sciences USA 102, 16701-16706 (2005).

62. J. D. Yeakel et al., Collapse of an ecological network in Ancient Egypt. Proceedings of the California Academy of Sciences 111, 14472-14477 (2014).

63. M. M. Pires et al., Pleistocene megafaunal interaction networks became more vulnerable after human arrival. Proceedings of the Royal Society B 282, DOI: 10.1098/rspb.2015.1367 (2015).

64. F. Schepers, W. de Bruijn, Rewilding Europe 2013 Annual Review. Rewilding Europe, Making Europe a Wilder Place 2014, 1-68 (2014).

65. H. W. Greene, in After preservation: saving American nature in the age of humans, B. A. M. a. S. J. Pyne, Ed. (University of Chicago Press, Chicago, 2015), pp. 105-113.

66. B. J. McGill, B. J. Enquist, E. Weiher, M. Westoby, Rebuilding community ecology from functional traits. Trends in Ecology \& Evolution 21, 178-185 (2006).

67. A. M. Lawing, J. J. Head, P. D. Polly, in Paleontology in Ecology and Conservation, J. Louys, Ed. (Springer-Verlag, Berlin, 2012), pp. 276.

68. P. D. Polly, J. J. Head, in Earth-Life Transitions: Paleobiology in the Context of Earth System Evolution, P. D. Polly, J. J. Head, D. L. Fox, Eds. (Yale Press, New Haven, 2015), vol. The Paleontological Society Papers 21, pp. 21-46. 
69. I. Žliobaite et al., Herbivore teeth predict climatic limits in Kenyan ecosystems. Proceedings of the National Academy of Science 113, 12751-12756 (2016).

70. P. D. Polly in Carnivoran evolution: new views on phylogeny, form, and function, A. Goswami, A. Friscia, Eds. (Cambridge University Press, Cambridge, 2010).

71. C. T. Webb, J. A. Hoeting, G. M. Ames, M. I. Pyne, N. L. Poff, A structured and dynamic framework to advance traits-based theory and prediction in ecology. Ecology Letters 13, 267-283 (2010).

72. A. Escudero, F. Valladares, Trait-based plant ecology: moving towards a unifying species coexistence theory. Oecologia 180, 919-922 (2016).

73. U. Ramakrishnan, E. A. Hadly, Using phylochronology to reveal cryptic population histories: Review and synthesis of four ancient DNA studies. Molecular ecology $\mathbf{1 8}$, 1310-1330. doi: 1310.1111/j.1365-1294X.2009.04092.x. (2009).

74. C. N. K. Anderson, U. Ramakrishnan, Y. L. Chan, E. A. Hadly, Serial SimCoal: A population genetics model for data from multiple populations and points in time. Bioinformatics 21, 1733-1734 (2005).

75. C. J. Donlan, De-extinction in a crisis discipline. Frontiers of Biogeography 6, 25-28 (2014).

76. A. E. Camacho, Going the way of the dodo: De-Extinction, dualisms, and reframing conservation. Washington Law Review 92, 849-906 (2015). 
77. J. HilleRisLambers, S. G. Yelenik, B. P. Colman, J. M. Levine, California annual grass invaders: the drivers or passengers of change? Journal of Ecology 98, 1147-1156 (2010).

78. F. P. Eigenbrod, P. Gonzalez, J. Dash, I. Steyl, Vulnerability of ecosystems to climate change moderated by habitat intactness. Global Change Biol 21, 275-286 (2015).

79. P. Gonzalez, R. P. Neilson, J. M. Lenihan, R. J. Drapek, Global patterns in the vulnerability of ecosystems to vegetation shifts due to climate change. Global Ecology and Biogeography 19, 755-768 (2010).

80. J. R. Stewart, A. M. Lister, I. Barnes, Refugia revisited: Individualistic responses of species in space and time. Proceedings of the Royal Society of London B 277, 661-671 (2010.).

81. J. L. McGuire, J. J. Lawler, B. H. McRae, T. A. Nuñez, D. M. Theobald, Achieving climate connectivity in a fragmented landscape. Proceedings of the National Academy of Science 113, 7195-7200 (2016).

82. D. G. Hole et al., Projected impacts of climate change on a continent-wide protected area network. Ecology Letters 12, 420-431 (2009).

83. E. Long, E. Biber, The Wilderness Act and climate change adaptation. Environmental Law 44, 623-694 (2014).

84. E. Biber, Adaptive management and the future of environmental law. Akron Law Review 46, 933-962 (2013). 
85. P. R. Ehrlich, P. M. Kareiva, G. C. Daily, Securing natural capital and expanding equity to rescale civilization. Nature 486, 68-73 (2012).

86. R. Costanza et al., Changes in the global value of ecosystem services. Global Environmental Change 26, 152-158 (2014).

87. M. C. Bottrill et al., Is conservation triage just smart decision making? Trends in Ecology \& Evolution 23, 649-654 doi: 610.1016/j.tree.2008.1007.1007 (2008).

88. SERI, in ISBN: 2-8317-0855-9, Society for Ecological Restoration International, IUCNCommission on Ecosystem Management (Clung Wicha Press Company, Ltd., Tucson, Arizona, USA and Gland, Switzerland, 2004), pp. http://www.ser.org/docs/defaultdocument-library/ser-iucn-global-rationale.pdf?sfvrsn=2.

89. S. Mondol, M. W. Bruford, U. Ramakrishnan, Demographic loss, genetic structure and the conservation implications for Indian tigers. Proceedings of the Royal Society B $\mathbf{2 8 0}$, 20130496 http://dx.doi.org/20130410.20131098/rspb.20132013.20130496 (2013).

90. F. E. Mayle, R. Burbridge, T. J. Killeen., Millennial-scale dynamics of southern Amazonian rain forests. Science 290, 2291-2294 (2000).

91. D. C. Morton, Y. L. Page, R. DeFries, G. J. Collatz, G. C. H. . Understorey fire frequency and the fate of burned forests in southern Amazonia. Philosophical Transactions of the Royal Society B 368, 20120163. doi:20120110.20121098/rstb.20122012.20120163 (2013). 
92. T. Fanin, G. R. v. d. Werf, Relationships between burned area, forest cover loss, and land cover change in the Brazilian Amazon based on satellite data. Biogeosciences 12, 60336043 (2015).

93. T. Hilker et al., Vegetation dynamics and rainfall sensitivity of the Amazon. Proc. Natl. Acad. Sci. U. S. A. 111, 16 041-016 046 (2014).

94. A. A. Alencar, P. M. Brando, G. P. Asner, F. E. Putz, Landscape fragmentation, severe drought, and the new Amazon forest fire regime. Ecological Applications 25, 1493-1505 (2015).

95. Y. Malhi et al., Exploring the likelihood and mechanism of a climate-change-induced dieback of the Amazon rainforest. Proc. Natl. Acad. Sci. U. S. A. 106, 20 610-620615. (2009).

96. J. Settele et al., in Intergovernmental Panel on Climate Change. Climate Change 2014: Impacts, Adaptation, and Vulnerability. (Cambridge University Press, Cambridge, UK, 2014).

97. T. W. Swetnam, Fire history and climate change in giant sequoia groves. Science $\mathbf{2 6 2}$, 885-889 (1993).

98. J. R. Marlon et al., Long-term perspective on wildfires in the western USA. Proc. Natl. Acad. Sci. U. S. A. 109, E535-E543 (2012). 
99. A. L. Westerling, M. G. Turner, E. A. H. Smithwick, W. H. Romme, M. G. R. 108:, Continued warming could transform Greater Yellowstone fire regimes by mid-21st century. Proc. Natl. Acad. Sci. U. S. A. 108, 13165-13170. (2011).

100. M. P. North et al., Reform forest fire management. Science 349, 1280-1281 ( 2015).

\section{Acknowledgements:}

We thank the financial sponsors of the workshop where these ideas were formulated: the Integrative Climate Change Biology Group, International Union of Biological Sciences; the Museum of Paleontology, Berkeley Initiative for Global Change Biology, and Office of the Vice Chancellor for Research at the University of California-Berkeley; the Conservation Paleobiology Group at the Department of Biology, Stanford University; and the Senckenberg Biodiversity and Climate Research Centre, Frankfurt, Germany. JJH and PDP were additionally funded by National Science Foundation ELT (Earth-Life Transitions) awards NSF EAR-1338028 (JJH) and NSF EAR-13388298 (PDP). ADB and CRM were partly funded by NSF EAR-1148181. We are especially grateful to V. Bowie for logistical support, and graduate student helpers A. Poust, S. Elshafie, and P. Kloess. We thank D. Thomas for his production of tiger maps that were modified for Figure 5 and the Howard Hughes Medical Institute for granting permission to use the maps (original versions at www.BioInteractive.org, copyright 2014, all rights reserved). E. Holt, N. Spano, B. Stein, Zixiang Zhang, and anonymous reviewers provided constructive comments. 
Table 1. Multiple Conservation Approaches

\section{Approach}

Examples

- Address root causes of conservation crisis through reducing the human footprint

- Increase the number of national parks and other protected areas and connections between them

- Quantify ecosystem services regionally and globally and value them in economic terms

- Abandon the idea of "pristine wilderness" and maintain high biodiversity (at genetic, population and species levels) in cultural landscapes

- Triage species interventions based on importance, uniqueness, or likelihood of success

- Relocate species, populations or genotypes whose habitats are disappearing in one place but emerging in another, especially where corridors are lacking

- Reconstruct or restore damaged or extinct ecosystems

- Manipulate populations and genetics of endangered species to enhance their survival

- Create ecosystems that simulate long-past conditions, such as Pleistocene rewilding.

- Produce facsimiles of extinct species through emerging techniques in molecular biology, e.g. "de-extinction" [not considered a viable conservation strategy in this paper, see text] 


\section{FIGURE LEGENDS}

Fig. 1. Critical conservation decisions. A, B, C, D and E indicate decision points where data from paleobiology are essential. Here "biodiversity" refers to all levels of the biological hierarchy. Novel ecosystems can serve to maximize biodiversity, particular ecosystem services, or ecosystem structure, which can be mutually exclusive, or which can overlap to varying degrees. The overlap of these conservation goals is typically broad in historical systems. For conserving historical ecosystems, taxon-based methods from paleobiology have already proven essential, and taxon-free methods also are useful. For novel ecosystems, taxon-free methods hold much potential for linking past, present, and future to help formulate effective conservation programs.

Fig. 2. Tracking community fluctuations through millennia. (A) Deposits accumulated by wood rats (Neotoma spp.) as they drag bone-laden carnivore scat and raptor pellets into their middens are particularly useful in sampling the vertebrate and plant community with high fidelity to taxonomic composition and relative abundance (46-48). Such records can provide successive snapshots of taxon presence, absence and abundance through thousands to millions (33) of years, and genetic variation (73) through thousands of years. Wood rat middens occur through much of North America; species in genera other than Neotoma construct paleoecologically useful middens elsewhere. (B) Bones excavated from a wood rat midden, after being concentrated by screening and sorting. $(\mathbf{C}, \mathbf{D}, \mathbf{E})$ Sediment cores from lakes contain fossil pollen and spores that allow reconstruction of vegetation changes through hundreds to hundreds of thousands of years (10). 
Fig. 3. Transformation of historical ecosystems. (A) Near Parque Nacional de Anavilhanas, Brasil, photo by Patrick Gonzalez. Palynological data revealed increased precipitation coincided with southern expansion of Amazon rainforest $\sim 3000$ years ago to its early $20^{\text {th }}$ century position (90). Reduced rainfall across two-thirds of the rainforest related to changes in the El NiñoSouthern Oscillation (91), combined with deforestation (92), have recently contributed to shifting the rainforest-savanna border northward, reduced vegetative productivity (93), increased fire frequency, and lengthened the fire season (94). Climate models suggest future transformation of vast areas of Amazon rainforest may be imminent $(95,96)$. (B) Las Conchas Fire near Bandelier National Monument, New Mexico, USA, photo by Kari Greer. Paleontological data show that western North American forest ecosystems depend on high-frequency, low-severity fires and that wildfire frequencies increased with drought $(97,98)$. Fuel buildup from fire suppression and anthropogenic climate change increased fire frequencies in the late $20^{\text {th }}$ century (99), and climate projections suggest that by 2100 fire frequency may increase to levels far above those to which historical and current vegetation have adapted (96). These considerations have been used to justify prescribed burning to pre-empt catastrophic crown fires (100).

Fig. 4. Ecometrics in paleobiology. (A) Proportions of certain bones are linked to land cover, land use, and topography through locomotor performance. (B) In mammalian carnivore communities, locomotor diversity can be measured using the in- and out-levers of the limbs and is linked to vegetation cover $(68,70)$; in snakes, the same relationship can be measured with the ratio of tail-to-body length (67). (C) Changes in the variance and mean of these traits can be assessed for congruence with changes in community composition and land cover. For example, 
when land acquired by the University of Kansas was allowed to revert from agricultural grassland to forest between 1947 and 2006, turnover in the herpetofauna changed the mean (black line) and standard deviation (grey bar) of tail-to-body ratios. (D) The change illustrated in panel $\mathrm{C}$ was congruent with ecometric values associated with grassland and forest ecosystems elsewhere (67). (E) Conversely, $19^{\text {th }}$-century deforestation of Indiana extirpated many large mammalian carnivores resulting in a loss of locomotor diversity, measured as the standard deviation (grey bars) of the out-to-in-lever ratio. (F) The loss of locomotor diversity can be mapped to identify other regions (dark gray shading) that may have been similarly affected (68).

Fig. 5. Pressures impacting wild tigers. (A) Only $\sim 3800$ wild tigers remain, confined to only $7 \%$ (dark green) of their historic (light green) geographic range. (B) Present geographic range of wild tigers (white outline) overlain on a map of crop and pasture lands (darker shades of purple indicate more intensive agricultural use), and on (C) (red outline) a map of human population density, where darker blues indicate higher density, ranging from $\leq 1$ person $/ \mathrm{km}{ }^{2}$ in the lightest colored regions to $>10,000$ people $/ \mathrm{km}^{2}$ in the darkest. Tigers remain mainly in the least densely populated areas, or in reserves located in novel ecosystems, such as (D) Ranthambore National Park, India. By 2050, at least half a billion more people are projected to populate regions that include tiger reserves.

Fig. 6. The importance of conservation corridors. Climate change and jurisdictional differences challenge corridor design. The Yellowstone to Yukon Conservation Initiative (purple outline) spans ecosystems rapidly transforming from increasing wildfire frequency and forest 
mortality, both triggered by global climate change, and two nations where private land confers varying property rights and federal protected areas are managed by different government agencies. While multiple jurisdictions complicate enhancing connectivity, such diversity can also contribute to success when the goals of maximizing biodiversity, ecosystem services, and preserving wilderness come into conflict, because each stakeholder may choose to optimize a different goal, while still contributing to the overall effect of providing a piece of the corridor. 


\section{Paleobiology for Conservation Decisions}

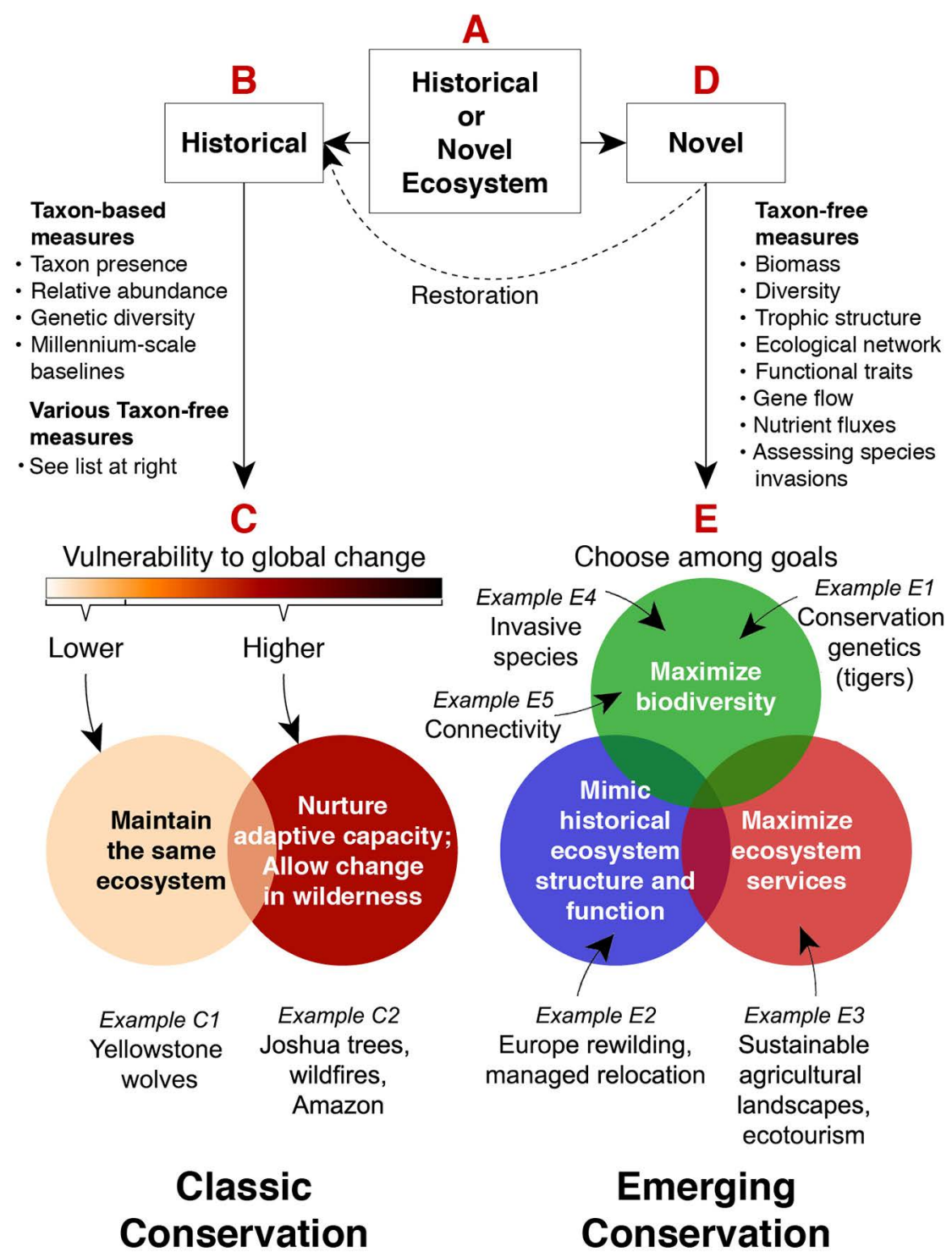




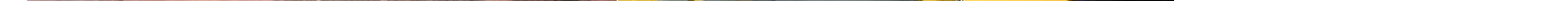


Ecometric

Trait

Functional

Factor

Direct

Environmental

Factors

Indirect

Environmenta Factors

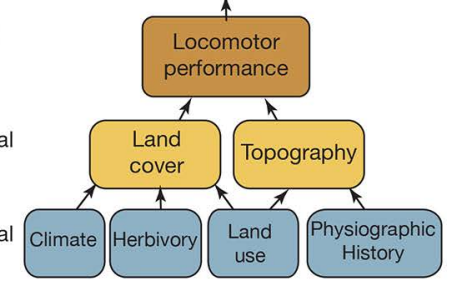

A
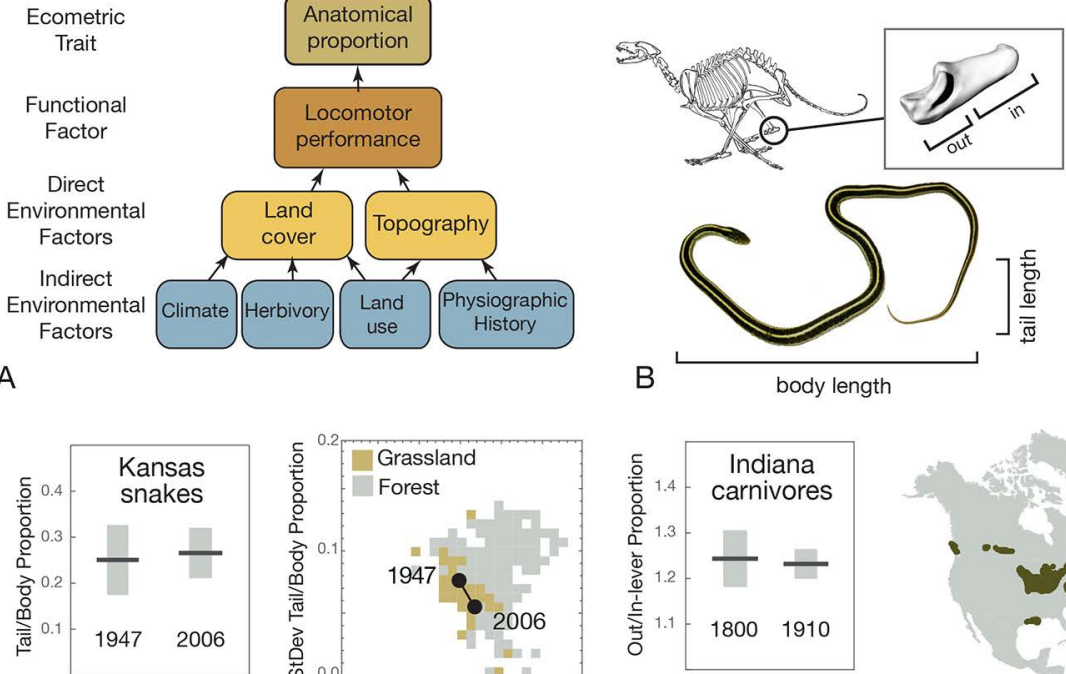

C

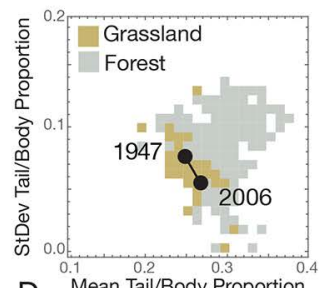

D Mean Tail/Body Proportion
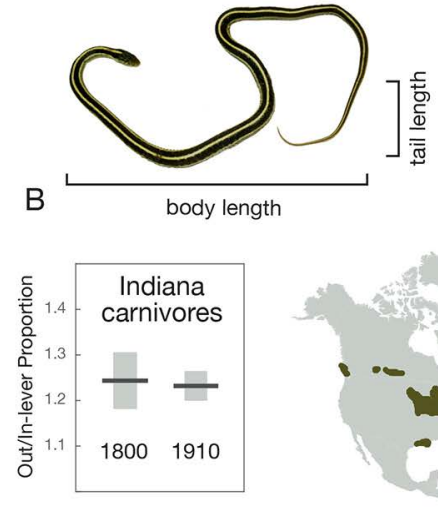

E 


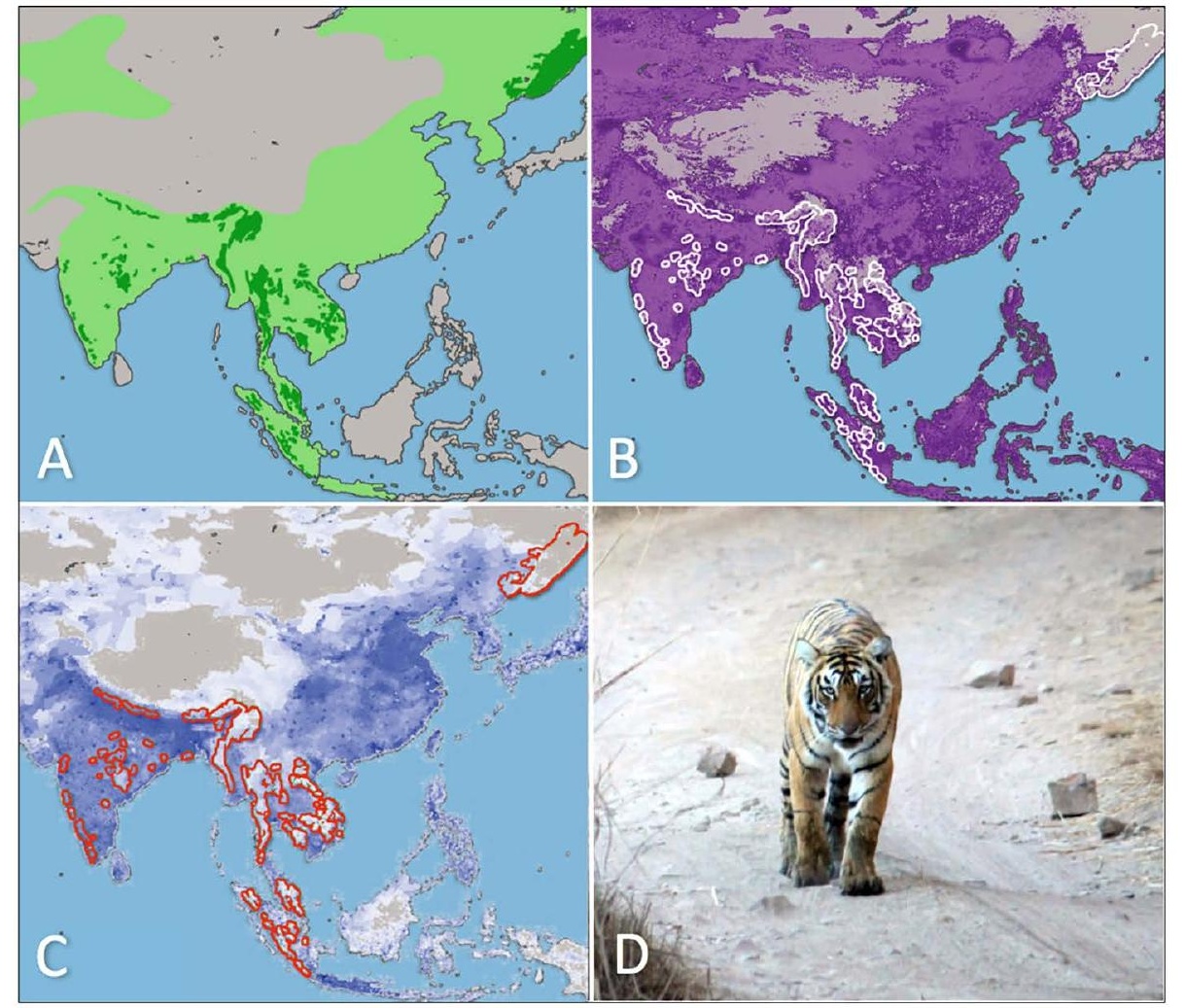




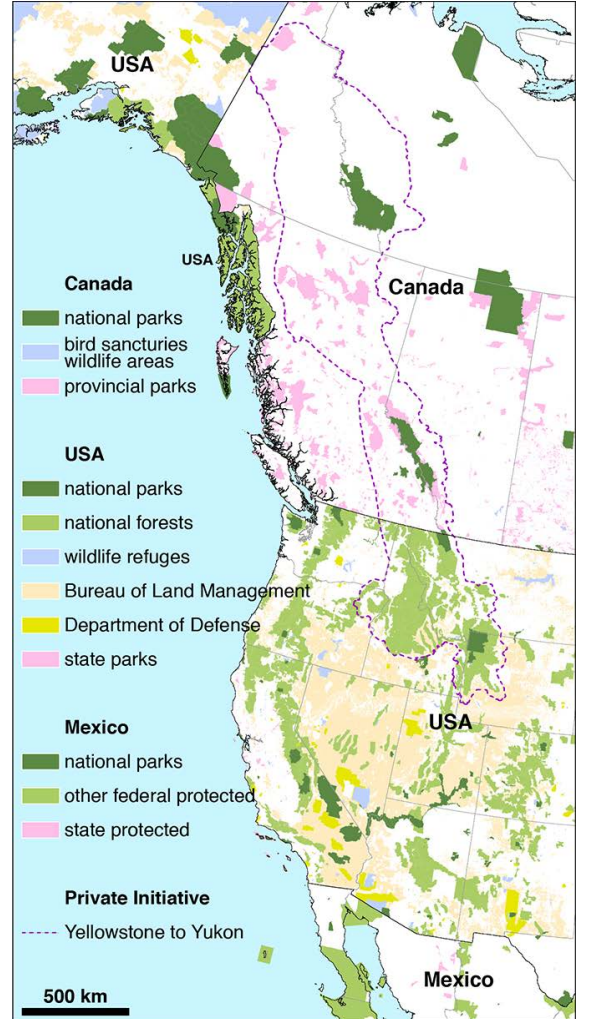

